the detrusor muscle may compensate for appreciable obstruction at the bladder neck; conversely, large residual amounts of urographic media may be found in the absence of true obstruction. ${ }^{9}$ Bladder calculi will be seen on the plain film and diverticula and tumours at cystoscopy - so that the only justification for routine urography becomes detection of incidental lesions. For no other condition is an investigation recommended simply because it might result in the chance finding of disease distant from the focus of clinical attention.

The investigation is positively indicated if a patient has haematuria, unexplained uraemia (up to $15 \mathrm{mmol} / \mathrm{l}$ ), urinary tract sepsis, or a history of renal disease or stones. Nevertheless, not surprisingly doctors are sometimes reluctant to condemn a patient to a long waiting list without some objective radiographic reassurance that a serious alternative explanation for the symptoms - such as a bladder tumour or early high pressure chronic retention-has not been overlooked.

Formal urodynamic evaluation is unnecessary in patients with uncomplicated prostatic hypertrophy. If a neurologically normal man over 60 with an enlarged prostate complains of hesitancy, frequency, and nocturia and has a poor independent urinary flow rate then he needs a transurethral resection. When irritative symptoms (frequency, urgency, urge incontinence) predominate, however, urodynamic assessment may be vital to avoid removing the prostate from a man with non-obstructive detrusor instability. Flow rate and pressure flow studies will usually suffice, and complex videocystometry should be reserved for equivocal cases. ${ }^{9}$

In most specialist urological units routine cross matching of blood for patients undergoing transurethral prostatectomy is no longer considered necessary. Grouping and saving the serum will suffice if an arrangement is made with the laboratory whereby blood can be made available at short notice. Blood should be cross matched for high risk groupsthe very frail, patients with anaemia or blood dyscrasias, or those with prostates estimated to weigh over $50 \mathrm{~g}$.

Clinical evaluation, examination for fitness for anaesthesia, basic blood tests, grouping and saving of serum, a plain abdominal radiograph, and bacteriological examination of the urine are all that should be required preoperatively in most patients admitted with acute urinary retention. What these patients need is a prompt return to life without a catheter. If malignancy is suspected, serum acid and alkaline phosphatase concentrations should be measured. Transrectal ultrasonography may be required, but bone scanning can wait until histological examination has confirmed malignancy. The same applies to patients with chronic retention, but renal function studies and urography or ultrasound should be conducted if upper tract dilatation is suspected and urodynamic studies if low pressure chronic retention is suspected. The man presenting with chronic symptoms of outlet obstruction requires the same assessment as the patient with acute retention. Urography, urodynamics, transrectal or abdominal ultrasonography, and computed tomography should be reserved for specific indications rather than used routinely as part of an irrationally overcomprehensive investigation programme.

P H O'REILLY

Consultant Urological Surgeon,

Stepping Hill Hospital,

Stockport SK2 7JE

1 Bauer DL, Garrison RW, McRoberts JW. The health and cost implications of routine excretory urography before transurethral prostatectomy. $\mathcal{F}$ Urol 1980;123:386-9.

2 Lucas MG, Bodley RW, Lindsell DRM, Fletcher EWL, Scott NP. Urography prior to prostatectomy. Postgrad Med f 1986;62:1117-9.
3 Pinck BD, Corrigan MJ, Jasper P. Pre-prostatectomy excretory urography. Does it merit the expense? J Urol 1980;123:390-3.

4 Brooman PJ, Griffiths GJ, Roberts EE, Peeling B, Evans KT. Transurethral ultrasonography in the evaluation of cancer of the prostate. In: Schulman CC, ed. Advances in diagnostic urologv. Berlin: Springer, 1981:158-68.

5 Rickards D, Gowland MR, Brooman PJC, Mamtoora H, Blacklock NJ, Isherwood I. Transrectal ultrasound and CT in the diagnosis of prostatic disease-a comparative study. Br $\mathrm{J}$ Urol 1983;55:726-32.

6 O'Reilly PH, Brooman PJC, Martin PJ, Pollard AJ, Farah NB, Mason GC. Accuracy and reproducibility of a new contrast clearance method for the determination of glomerular filtration rate. BrMed J 1986;293:234-6.

7 O'Reilly PH, Shields RA, Testa HJ, eds. Nuclear medicine in urologv and nephrologv. London Butterworths, 1986.

8 George NJR, O'Reilly PH, Barnard RJ, Blacklock NJ. High pressure chronic retention. Br Med J $1983 ; 286: 1780-3$.

9 George NJR. Lower urinary tract obstruction. Basic Considerations. In: O'Reilly PH, ed. Obstructive uropathy. Berlin: Springer, 1986:197-233.

\section{The search for a hormonal switch for obesity}

Very rarely is obesity caused by a primary endocrine disturbance such as hypothyroidism or hypercorticolism, and most patients do not have any obvious cause, hormonal or otherwise. ${ }^{1}$ Feeding behaviour in man is controlled by a multiplicity of signals, but the search has continued for a peptide that might finally control appetite. We do not seem to be near to finding such a peptide.

The regulation of feeding behaviour is highly complex since the conscious appreciation of hunger and satiety is dependent on so many factors including genetic predisposition, ${ }^{2}$ all the senses, mood, cultural habits, socioeconomic status, intercurrent illness, and, last but not least, food availability. ${ }^{3}$ The functional distinction between a ventromedial hypothalamic satiety centre and a ventrolateral hypothalamic feeding centre has served as a valuable experimental model $^{+}$and may be relevant in certain types of genetically obese mice as well as in the rare cases of hypothalamic obesity in man. ${ }^{5}$ Other brain areas, however, are also important in feeding behaviour, especially the paraventricular nucleus of the hypothalamus, the globus pallidus, and the amygdala. ${ }^{3}$ These hypothalamic centres may sort and integrate afferent information from both the periphery and other brain regions. The centres produce an efferent autonomic response as well as a conscious appreciation of the need to eat.

Many hypotheses have tried to provide an all embracing explanation for appetite regulation and its disorders, but we are not as simple as the mollusc pleurobranchea, which eats everything in sight until its appetite is switched off by its egg laying hormone. ${ }^{6}$ In man we must consider the afferent input from taste, smell, and sometimes even auditory and visual stimuli. Additionally there are important autonomic afferent signals from stomach, gut, and perhaps liver that may interact with messages (dependent on specific hypothalamic receptors) from certain nutrients and metabolites such as glucose, glycerol, amino acids, and possibly free fatty acids. ${ }^{3.9}$

Against this complex background are feedback signals mediated by classical hormones both old and new, and since many of the peptide hormones are synthesised in both the brain and the periphery (especially the gut and pancreas) there is much speculation on the specific production and target sites in relation to appetite control. Important among these are thyroid hormones ${ }^{10}$ and glucocorticoids," which stimulate appetite, and cholecystokinin, bombesin, somatostatin, and pancreatic glucagon, all of which can produce some degree of satiety. ${ }^{2}$ Although in man 
exogenous insulin stimulates appetite,${ }^{13}$ giving insulin intracerebroventricularly to rats suppresses it ${ }^{1+} ;$ and rats treated with antiinsulin antibodies show an increase in food intake. ${ }^{15}$ Knoll has claimed the existence in human serum of a potent anorexigenic glycoprotein-with a molecular weight of 40 000-60 000 and comprising $87 \%$ carbohydrate and $12 \cdot 8 \%$ amino acids - that he has named "satietin." ${ }^{\prime \prime 6}$ Full characterisation and further confirmatory studies are now required. Most recently a polypeptide produced by macrophages has been isolated that can induce a severe cachetic and shock like state when given to experimental animals; it also has widespread effects on the immune system. ${ }^{1722}$ This molecule, named "cachectin," is identical to tumour necrosis factor and may play a part in the cachexia and weight loss associated with malignancies. ${ }^{22}$

Within the hypothalamus there appear to be important ventromedial serotoninergic and ventrolateral dopaminergic inputs with possible inhibitory gabaergic interneurones. ${ }^{23}$ But many neurotransmitters or neuropeptides have been reported to exert some effect on appetite when given either peripherally or intracerebroventricularly. Most are inhibitory including corticotrophin releasing factor, vasoactive intestinal peptide, thyrotrophin releasing hormone (and its metabolite cyclo-histidyl-proline-diketopiperazine), neurotensin, bombesin, calcitonin, calcitonin gene-related peptide, somatostatin, and cholecystokinin; but opioid peptides (particularly dynorphin, the endogenous ligand for $\mathrm{K}$ opioid receptors), encephalins, and growth hormone releasing factor are stimulatory. ${ }^{312} 23.26$

Obese patients often have altered basal and stimulated hormone concentrations, including hyperinsulinaemia with peripheral insulin resistance, increased cortisol turnover with reduced adrenocorticotrophic hormone responses, and impaired growth hormone and prolactin responses to most provocative stimuli.' Such secondary hormonal changes may each serve to exacerbate the primary disorder, and obese patients deal less efficiently with a calorie load than a lean individual..$^{27}$ Hyperinsulinaemia also occurs in certain rodent models of obesity through a cholinergic mechanism and may mediate the obesity in some but not all experimental animal models. ${ }^{28}$ Because of the difficulty in assessing hypothalamic function in man some investigators have studied the regulation of anterior pituitary hormones. These patients show an appreciable impairment of growth hormone responses to all provocative stimuli, ${ }^{1}$ including growth hormone releasing factor. ${ }^{29}{ }^{30}$ The findings of reduced prolactin responses to insulin hypoglycaemia and thyrotrophin releasing hormone in obese patients are more conflicting. This lack of responsiveness may be caused by alterations to specific neurotransmitter pathways, hypothalamic peptide release, or pituitary function itself or by some other alteration in peripheral feedback signals. Such findings have led some to postulate a primary hypothalamic defect in obesity, but this seems unlikely since most changes occur as a consequence of obesity and return to normal after loss of body weight. ${ }^{127}$ Recently a small subgroup has been identified in whom the impaired prolactin response to insulin hypoglycaemia is not apparently reversible by weight loss. ${ }^{31}{ }^{32}$ Whether or not this reflects an endogenous hypothalamic defect in some patients remains to be established since no long term follow up data are yet available.

In conclusion, there have been no dramatic breakthroughs in understanding and no revolutionary new concepts but rather a steady accumulation of data confirming the multiplicity of interacting factors that control feeding behaviour. If most human obesity is anything other than the consequence of a variably reduced individual ability to control a pleasant appetite and to balance intake and expenditure, then there are an enormous number of potential malfunctions that may each require highly specific treatment. Despite this the search continues for an overriding final mediating peptide that can switch off the feeding centre or switch on the satiety centre. The ability to control or administer such a peptide could provide a simple therapeutic approach.

C Dieguez

Research associate M F SCANLON

Neuroendocrine Unit,

Reader in medicine

Department of Medicine,

University of Wales College of Medicine,

Cardiff CF4 4XN

1 Jung R. Endocrinological aspects of obesity Clin Endocrinol Metab 1984:13.597-612.

2 Stunkard AJ, Sorensen TIA, Hanis C, et al. An adoption study of human obesity. N Engl f Med 1986;314:193-8.

3 Morley JE, Levine AS, Gosnell BA, Billington CJ, Krahn DD. Control of food intake. In: Muller EE, MacLeod RM, Frohman LA. Neuroendocrine perspectives Vol 4: Amsterdam: Elsevier, 1985: $145-90$.

4 Assimacopoulos-Jeannet F, Jeanrenaud B. The hormonal and metabolic basis of human obesity. Clin Endocrinol Metab 1976;5:337-65.

5 Bray GA, Gallagher TF. Manifestations of hypothalamic obesity in man. A comprehensive investigation of eight patients and a review of the literature. Medicine 1975;54:301-30.

6 Davis WJ, Mpitsos GJ, Pinneo JM. The behavioural hierarchy of the mollusk pleurobranchea. Hormonal suppression of feeding associated with egg laying. Foumal of Comparative Physiology Hormonal supp

Wurtman RJ. Behavioural effects of nutrients. Lancet 1983;ii:1145-7.

8 Racotta R, Russek M. Food and water intake of rats after intraperitoneal and subcutaneous administration of glucose, glycerol and sodium lactate. Physiol Behav 1977;18:267-73.

LeMagnen J. Body energy balance and food intake: a neuroendocrine regulatory mechanism. Physiol Rev 1983;63:315-86.

10 Morley JE, Elson MK, Levine AS, Shafer RB. Levels of irdynorphin in brain and pituitary of hyperthyroid and hypothyroid rats. Eur f Pharmacol 1982;78:125-7.

11 Levine AS, Morley JE. Adrenal modulation of opiate induced feeding. Pharmacol Biochem Behav 1983;19:403-6.

12 Smith GP, Gibbs J. Gut peptides and postprandial satiety. Fed Proc 1984;43:2889-92.

13 Levine AS, Morley JE. Peptidergic control of insulin-induced feeding. Peptides 1981;2:261-4.

14 Ikeda H, West DB, Pustik JJ, Woods SC. Insulin infused intraventricularly reduces food intake and body weight of lean but not obese ( $\mathrm{fa} / \mathrm{fa}$ ) zucker rats. Diabetes 1983;32:61 A

15 Strubbe JH, Mein CG. Increased feeding in response to bilateral injection of insulin antibodies in the VMH. Physiol Behav 1977;17:309-14.

16 Knoll J. Satietin: a highly potent anorexigenic substance in human serum. Physiol Behav 1979;23:497-502.

17 Pennica D, Nedwin GE, Hayflick JS, et al. Human tumour necrosis factor: precursor structure, expression and homology to lymphotoxin. Nature 1984;312:724-9.

18 Gray PW, Aggarwal BB, Benton CV, et al. Cloning and expression of cDNA for human lymphotoxin, a lymphokine with tumour necrosis activity. Nature 1984;312:721-4.

19 Torti FM, Dieckmann B, Beutler B, Cerami A, Ringold GM. A macrophage factor inhibits adipocyte gene expression: an in vitro model of cachexia. Science 1985;229:867-9.

20 Takeda $\mathrm{K}$. Iwamoto $\mathrm{S}$, Sugimoto $\mathrm{H}$, et al. Identity of differentiation inducing factor and tumour necrosis factor. Nature 1986;323:338-40.

21 Philip R, Epstein LB. Tumour necrosis factor as immunomodulator and mediator of monocyte cytotoxicity induced by itself, $\alpha$-interferon and interleukin-1. Nature 1986;323:86-9.

22 Cerami A. Cachectin: a macrophage protein that induces a catabolic state. In: Procecdings of 68th annual meeting of the Endocrine Societv, Anaheim 1986. Bethesda, Maryland: Endocrine Society, 1986:17.

23 Morley JE, Levine AS, Gosnell BA, Billington CJ. Neuropeptides and appetite: contribution of neuropharmacological modelling. Fed Proc 1984;43:2903-7.

24 Baile CA, Della-Fera MA. Peptidergic control of food intake in food-producing animals. Fed Proc 1984;43:2898-902

25 Yim GKW, Lowy MT. Opioids, feeding and anorexias. Fed Proc 1984;43:2893-7.

26 Imaki T, Shibasaki T, Hotta $M$, et al. The satiety effect of growth hormone-releasing factor in rats. Brain Res 1985;340:186-8.

27 Sims EAH, Danforth E, Hørton ES, Bray GA, Glennon JA, Salans LB. Endocrine and metabolic effects of experimental obesity in man. Recent Prog Horm Res 1973;29:457-96.

28 Inoue S, Mullen YS, Bray GA. Hyperinsulinaemia in rats with hypothalamic obesity: effects of autonomic drugs and glucose $A m \mathcal{F}$ Physiol 1983;245:R372-8.

29 Williams ST, Berelowitz M, Joffe SN, et al. Impaired growth hormone responses to growth hormone releasing factor in obesity. N Engl f Med 1984;311:1403-7.

30 Kopelman PG, Noonan K, Goulton R, Forrest AJ. Impaired growth hormone response to growth hormone releasing factor and insulin-hypoglycaemia in obesity. Clin Endocrinol 1985;23:87-94

31 Kopelman PG, White N, Pilkington TRE, Jeffcoate SL. Impaired hypothalamic control of prolactin secretion in massive obesity. Lancet 1979; i:747-9.

32 Kopelman PG, Pilkington TRE, Jeffcoate SL, White N. Persistence of defective hypothalamic control of prolactin secretion in some obese women after weight reduction. $\mathrm{Br}$ Med $\mathcal{J}$ 1980;281:358-9. 